\title{
INFRAESTRUTURA URBANA SUSTENTÁVEL: CONCEITOS E APLICAÇÕES SOB A PERSPECTIVA DO ARQUITETO E URBANISTA
}

\author{
Ariadne S. de Farias ${ }^{1}$ \\ Joceane P. Marcon ${ }^{2}$ \\ Débora P. Schmitt ${ }^{3}$ \\ Karen M. Siebeneichler ${ }^{4}$
}

DOI: 10.5752/P.2316-1752.2017v25n36p164

\section{Resumo}

Este artigo tem como objetivo destacar a contribuição da infraestrutura verde para o desenvolvimento sustentável das cidades. A partir de conceitos, tipologias e aplicações, demonstra a emergência da aplicação dos preceitos da sustentabilidade para transformar a paisagem, em busca da construção da resiliência urbana. Portanto, o arquiteto e urbanista possui um papel fundamental no planejamento e implantação da infraestrutura verde, além da função de

1. Geógrafa, Licenciada e Mestra em Geografia. Doutoranda em Meio Ambiente e Desenvolvimento pela Universidade Federal do Paraná - UFPR. Foi bolsista CAPES. E-mail: ariadnegeo21@gmail.com

2. Arquiteta e Urbanista pela Unipar/Francisco Beltrão-PR. Pós-Graduada em Arte-Educação pela ISULPAR. E-mail: joceanepmarcon@gmail.com

3. Arquiteta e Urbanista pela Unipar/Francisco Beltrão-PR. E-mail: deboraschmitt007@ hotmail.com

4. Arquiteta e Urbanista pela Unipar/Francisco Beltrão-PR. E-mail: karenmaisasieb@ gmail.com 
despertar o interesse da sociedade para a transformação do ambiente urbano em prol de uma melhor qualidade de vida nas cidades.

Palavras-chave: Infraestrutura urbana. Sustentabilidade. Urbanismo. 


\section{SUSTAINABLE URBAN INFRASTRUCTURE: CONCEPTS AND APPLICATIONS FROM THE PERSPECTIVE OFTHE ARCHITECT AND URBAN PLANNER}

\begin{abstract}
This article aims to highlight the green infrastructure contribution to a sustainable development of the cities. Considering concept, typologies and applications, demonstrates the emergence of the sustainable precepts application to transform the landscape, in search of urban resilience building. Therefore, the architect and urbanist have a key role in the planning and implementation of green infrastructure, in addition to awakening the society interest to the transformation of the urban environment for a better quality of life in cities.
\end{abstract}

Keywords: Urban infrastructure. Sustainability. Urbanism.

\section{INFRAESTRUCTURA URBANA SOSTENIBLE: CONCEPTOS Y APLICACIONES DESDE LA PERSPECTIVA DEL ARQUITECTO Y URBANISTA}

\section{Resumen}

Este artículo pretende destacar la aportación de infraestructura verde para un desarrollo sostenible de las ciudades. Teniendo en cuenta concepto, tipologías y aplicaciones, se muestra la aparición de la aplicación de preceptos sostenible para transformar el paisaje, en busca de la construcción de resiliencia urbana. Por lo tanto, el arquitecto y urbanista tienen un papel clave en la planificación y ejecución de la infraestructura verde, además de despertar el interés de la sociedad en la transformación del entorno urbano para una mejor calidad de vida en las ciudades.

Palabras-claves: Infraestructura urbana. Sustentabilidad. Urbanismo. 


\section{Introdução}

Neste início do século XXI, observa-se que grande parte das sociedades urbanas está enfrentando um aumento acentuado dos problemas socioambientais, tanto nas grandes metrópoles mundiais como nos pequenos e médios centros urbanos regionais. A crise urbana contemporânea é, segundo Rattner (2009), consequência de um modelo arcaico e irracional de ocupação do espaço urbano e protagoniza uma ampla agenda de debates acerca das mudanças ambientais globais.

No Brasil, as transformações em torno da relação sociedade-natureza foram impulsionadas pelo rápido processo de urbanização, concentração dos equipamentos e serviços em áreas de relevante interesse econômico, instalação de polos industriais em áreas de fragilidade ambiental e pelo aumento considerável da população urbana. Acselrad (2009) relata que, nos últimos 50 anos, o processo de crescimento urbano mundial foi maior que o aumento da população. Na última década, enquanto a população total cresceu aproximadamente $20 \%$ (vinte por cento), a população urbana cresceu mais que $40 \%$ (quarenta por cento). Na maioria dos casos, esse processo de urbanização manifesta problemas nas cidades, exigindo sistemas adequados de transporte público, infraestrutura básica para promover educação, saúde, habitação, saneamento, segurança e em- 
prego para os citadinos.

Acselrad (2009) define o crescimento urbano como um fenômeno com efeitos antagônicos: de um lado, as economias de escala e externalidades oferecem benefícios ilimitados e promissores; do outro, tendem a produzir custos ambientais e sociais aparentemente positivos, mas que ao longo do tempo incluem resultados que afetam diretamente a qualidade de vida das pessoas.

Herzog (2010) apresenta o modelo de urbanização tradicional, constituído pela infraestrutura "cinza", formada, basicamente, pelas ruas asfaltadas e os automóveis, incentivando o mercado do automóvel e a economia em grande escala. Hisayasu e Pellegrino (2009) alertam que os sistemas de infraestruturas convencionais não aproveitam os elementos naturais da paisagem, causando danos ao ecossistema urbano, como, por exemplo, diminuição das áreas verdes urbanas, contaminação dos solos, poluição do ar, comprometimento da qualidade das águas superficiais e subterrâneas, entre outros problemas.

A preocupação em torno da problemática socioambiental das cidades tem sido destaque na mídia mundial, cabendo ao aquecimento global e às mudanças climáticas a justificativa para a maioria das catástrofes e prejuízos econômicos, sociais e ambientais ocorridos. Trata-se, também, de 
um tema estudado frequentemente entre os pesquisadores mundiais. Para Herzog e Rosa (2010), as mudanças climáticas estão mais visíveis, pois se tornam cada vez mais frequentes e mais intensas as tempestades, as ressacas marítimas, os ventos e as secas, constatando, assim, áreas urbanas mais vulneráveis a essas ocorrências. Além das ocorrências de chuvas mais fortes, inundações e deslizamentos, ainda se tem o aumento da temperatura, formando as ilhas de calor. A infraestrutura "cinza" substitui a paisagem do sítio natural pela paisagem urbana construída, acentuando os efeitos do microclima urbano, um dos mais graves problemas causados pelas técnicas do urbanismo tradicional.

Diariamente, é registrada, em diversas cidades brasileiras, a ocorrência de desastres provocados por eventos climáticos extremos, como tempestades, inundações e alagamentos, deslizamentos, chuva de granizo, escassez de água, etc. Assim, surge a emergência de adaptar as cidades, de modo a reduzir a vulnerabilidade da população e a mitigar os impactos dos eventos críticos - aqueles com potencial de prejuízos econômicos, sociais e ambientais. Porém, na atual conjuntura, é perceptível a dificuldade de gerenciamento dos sistemas de infraestruturas urbanos, devido à falta ou ineficácia de um planejamento a priori.

A problemática socioambiental urbana, ou seja, os conflitos 
sociais, econômicos, políticos, culturais e ambientais, associados à relação sociedade-natureza no ambiente urbano, contempla diferentes escalas de análise, perpassa diversas áreas do conhecimento e constitui um tema de preocupação emergente aos planejadores urbanos. Segundo Lemos (2010), o contexto em que os problemas estão inseridos, embora seja global, deve ser considerado no planejamento local das cidades, onde acontece o uso e a ocupação do solo conforme as peculiaridades histórico-culturais, a conjuntura socioespacial e a configuração política e socioeconômica urbana.

A expansão desordenada da malha urbana ameaça a qualidade de vida nas cidades e no campo, considerando que, na maioria das vezes, a gestão adequada e a conservação dos ecossistemas são negligenciadas em função do valor de uso da terra. A utilização inadequada dos recursos naturais, a ausência de regulamentação do uso do solo e de uma fiscalização efetiva, aliados à falta de planejamento dos sistemas de infraestrutura urbana, podem ocasionar conflitos significativos e gerar graves prejuízos sociais, econômicos e ambientais.

Diante dos conflitos socioambientais gerados pelo crescimento urbano, a infraestrutura verde, proposta por Herzog (2010), possibilita a mitigação dos impactos negativos da urbanização, ao proporcionar alternativas de baixo consu- 
mo e eficiência energética, menor emissão dos gases de efeito estufa, estratégias de conservação e proteção da biodiversidade, e de prevenção e/ou diminuição da poluição das águas, do ar e do solo, entre outros. Constitui-se em uma rede multifuncional de espaços abertos, em que se adapta os processos naturais nas áreas urbanas, que desempenham funções ecológicas, sociais, econômicas e culturais.

Nesse contexto, o presente artigo tem como objetivo destacar a contribuição dos equipamentos e serviços preconizados pela infraestrutura verde, bem como a importância das práticas emergentes de planejamento e gestão que buscam conduzir à tão almejada sustentabilidade urbana. A partir de uma revisão bibliográfica acerca do tema proposto, o trabalho encontra-se dividido em três partes: na primeira, são apresentados os conceitos de sustentabilidade e de resiliência urbana, buscando compreender alguns aspectos inerentes à relação sociedade-natureza nas cidades. Na sequência, o papel do planejamento urbano e a concepção de paisagens de alto desempenho são apresentados enquanto estratégia para a elaboração dos projetos de intervenção urbana. A terceira parte do artigo apresenta o conceito de "infraestrutura sustentável" ou "infraestrutura verde" (Herzog, 2013; 2010), além de apresentar alguns exemplos da eficiência aplicados aos sistemas urbanos de infraestrutura. Por fim, o papel do arquiteto e urbanista no 
planejamento e gestão dos sistemas de infraestrutura urbana ganha destaque nas considerações finais.

\section{Sustentabilidade e resiliência urbana}

O tema sustentabilidade vem sendo evidenciado frequentemente em todas as áreas, na administração, na economia, na engenharia, na arquitetura e, inclusive, no direito. Batista, Cavalcanti e Fyjihara (2005), em seu livro "Caminhos da Sustentabilidade no Brasil," explicam como surgiu o termo e o significado de sustentabilidade. A norueguesa Gro Brundtland (médica e política) definiu o termo desenvolvimento sustentável como uma "necessidade do presente 172 sem comprometer a sobrevivência das gerações futuras". O termo foi oficialmente aceito em 1990 e oficializado pela ECO-92 (II Conferência das Nações Unidas sobre Meio Ambiente e Desenvolvimento, no Rio de Janeiro).

Para Cabrera (2009), o conceito, que já faz parte da vida moderna, traz um significado sistêmico correlacionando e integrando os aspectos econômicos, sociais, culturais e ambientais da sociedade. Faz-se necessário entender o progresso global em uma época de recursos naturais escassos, relacionando o meio ambiente com todas as áreas da atividade humana. Bonder (2003) afirma que a sociedade sustentável deve estar fundamentada na equidade e na justiça social. Assim, valores precisam ser resgatados no 
contexto da sociedade moderna, uma sociedade caracterizada pela concentração de riquezas, centralização de poder, consequente segregação de classes e exclusão dos menos favorecidos. O resgate desses valores requer um esforço coletivo de mobilização, motivação e de participação de todos os cidadãos para a construção de uma sociedade próspera economicamente durável.

Acselrad (1999) entende que a sustentabilidade, aplicada ao espaço urbano, compreende desde a administração dos riscos e incertezas à capacidade de se adaptar às estruturas urbanas. Tudo está interligado: a gestão dos fluxos de energia; os materiais associados ao crescimento urbano; a eficiência do sistema, o qual não deve provocar desperdícios; a escala urbana, que limita o crescimento econômico e o uso dos recursos escassos. Bonder (2003) afirma que a sociedade sustentável deve estar fundamentada na equidade e na justiça social. Da mesma forma, Acselrad (1999) observa que a justiça social e a conservação ambiental são premissas que devem ser tratadas de forma integrada.

Portanto, a noção de desenvolvimento sustentável implica uma conjuntura entre a justiça social, qualidade de vida, equilíbrio ambiental e a necessidade de desenvolvimento, que se sustente econômica e financeiramente. Deve-se enfatizar as práticas pautadas por um desenvolvimento de políticas sociais que se articulam com a necessidade de 
recuperação, conservação, melhoria do meio ambiente e da qualidade de vida. (JACOBI, 1999, p. 44).

Ao lançar um olhar crítico em relação ao crescimento da população urbana, apesar de toda a evolução tecnológica e social, percebe-se que os problemas socioambientais, além de não serem solucionados, foram com o tempo se agravando significativamente. Demantova (2012) aborda o tema com propriedade ao afirmar que, com a velocidade em que foram transformados o meio natural e o ambiente construído mesmo com algumas ações praticadas para reduzir os impactos socioambientais, torna-se mais difícil reverter a degradação ambiental.

No que tange à sustentabilidade urbana, um aspecto relevante constitui o meio da construção civil, atividade que utiliza recursos naturais e que, na maioria dos casos, gera resíduos de grande impacto ambiental. Acerca dessa problemática, Karpinsk et al. (2009, p.13) afirmam que:

(...) a cadeia produtiva da construção civil é responsável por uma quantidade considerável de resíduos de construção e demolição (RCD) depositados em encostas de rios, vias e logradouros públicos, criando locais de deposições irregulares nos municípios.

A preocupação nesse caso é que a paisagem e a qualidade ambiental das cidades acabem sendo comprometidas, uma vez que os resíduos da construção civil não recebam 
o tratamento e/ou a destinação adequada. É comum observar grande volume de resíduos dispostos em locais inapropriados, próximo aos canteiros das obras em regiões periféricas e próximo às áreas de fragilidade ambiental (corpos hídricos, planícies fluviais, estuários, etc.), além da obstrução dos sistemas de drenagem urbana. Associados à aglomeração dos resíduos, podem surgir problemas como doenças ocasionadas por organismos vetores e a degradação de áreas urbanas, afetando a qualidade de vida da sociedade como um todo (KARPINSK et al., 2009). Jacobi (2003, p.200) traz à discussão o despertar ecológico como fator primordial para manter a qualidade de vida nas cidades, ao afirmar que:

(...) é necessário fortalecer a importância de garantir padrões ambientais adequados e estimular uma crescente consciência ambiental, centrada no exercício da cidadania e na reformulação de valores éticos e morais, individuais e coletivos, numa perspectiva orientada para o desenvolvimento sustentável.

Problemas como o esgotamento dos recursos naturais (matéria-prima), poluição do ar, enchentes, alagamentos e inundações, contaminação das águas e do solo, desmatamento e pressão sobre o uso e ocupação do solo em áreas legalmente protegidas, desastres ambientais, comprometimento da saúde da população, entre outros, estão associados aos custos socioambientais. 
A implementação de planos visando o correto manejo de resíduos, uso de energia limpa, diminuição da emissão de gases, melhoria na mobilidade urbana (ciclovias, ciclofaixas), construções sustentáveis com sistemas econômicos de utilização de água e luz, assim como a infraestrutura verde, mostra-se eficiente para o crescimento sustentável das cidades, ajudando na melhoria da qualidade de vida dos citadinos.

Os problemas da sociedade moderna podem ser amenizados ou até mesmo resolvidos a partir de uma ação conjunta entre os habitantes e os governantes. De um lado, os habitantes que possuem direitos e deveres; e do outro, um governo que promova planejamento e projetos sustentáveis, resgatando os valores para a construção de uma sociedade próspera economicamente durável, ou seja, uma cidade sustentável.

Considerando a complexidade dessas e de inúmeras outras questões relacionadas à problemática urbana, vale destacar que este artigo não tem a pretensão de trazer soluções técnicas, ou ainda metodológicas. O intuito aqui é o de lançar uma reflexão e apresentar alguns pressupostos da infraestrutura como um sistema técnico do desenho urbano que pode (e deve) fazer parte do planejamento das atividades antrópicas e da gestão sustentável da urbe. Para tanto, entende-se que o sistema urbano de infraestrutura, 
com vistas ao ordenamento sustentável das ações sobre o espaço urbano, é um elemento essencial para a transformação das cidades.

Uma abordagem dos estudos socioambientais urbanos enfatiza que a transformação tão almejada das cidades seria possível por meio do fortalecimento das forças locais de atuação a partir da construção da resiliência urbana. Órgãos internacionais, como a Organização das Nações Unidas - ONU -, por exemplo, promovem campanhas junto aos gestores públicos de diversos países, especialmente dos países com maiores taxas de vulnerabilidade social, econômica e ambiental frente a eventos extremos associados aos desastres naturais e aos problemas socioambientais cotidianos.

Mendonça (2015, p.49) esclarece que o termo resiliência refere-se, de maneira geral, "à capacidade de resistência de um dado objeto, organismo ou pessoa, a um determinado impacto". De acordo com Silva (2014), existem diversos significados para resiliência, dependendo da área na qual irá se inserir o conceito. No contexto ambiental, a resiliência é a aptidão de um determinado sistema que lhe permite recuperar o equilíbrio depois de ter sofrido uma perturbação. Portanto, o conceito remete para a capacidade de restauração de um sistema. Assim, a noção de resiliência urbana pode ser definida como a capacidade que uma cidade tem 
de resistir, absorver, adaptar-se e recuperar-se da exposição às ameaças, produzindo efeitos de maneira oportuna e eficiente, o que inclui a preservação e restauração de suas estruturas sociais e ecológicas, ou seja, dos fatores e agentes dinamizadores das funções básicas desempenhadas no ambiente urbano.

De acordo com Furtado (2015, p. 28), as discussões acerca da resiliência da população frente aos problemas socioambientais urbanos e suas "(...) relações com a governança, colocam o elemento humano como fator preponderante para a resiliência das cidades, destacando a centralidade das questões culturais e de relação com as instituições, inclusive as governamentais". Surge, então, a necessidade de um (re)planejamento adequado para a construção da resiliência socioambiental urbana, por meio do diálogo entre os gestores públicos, a população local e os profissionais especializados em estudos urbanos, que possam fazer a intermediação entre a gestão dos recursos naturais disponíveis e a ordenação das atividades antrópicas desenvolvidas nas cidades. Parece simples, porém depende de uma série de fatores que envolvem sociedade, economia, gestão e interesses.

É importante ressaltar, ainda, que as diferentes concepções sobre o que seja a sustentabilidade urbana apontam para a reprodução adaptativa das estruturas urbanas com 
enfoque no reajustamento da base técnica das cidades, nos princípios que fundamentam o exercício da cidadania das populações urbanas e/ou na redefinição das bases de legitimidade das políticas urbanas (ACSELRAD, 1999). Assim, as noções de sustentabilidade e de resiliência podem ser empregadas nas diretrizes do planejamento urbano de modo a articular as estratégias argumentativas de adaptação social à crescente preocupação em torno da conservação ambiental e da emergencial mitigação dos conflitos socioambientais urbanos.

Ao analisar as argumentações anteriores, entende-se que o arquiteto pode ser considerado um profissional intermediador, qualificado para atuar nos diferentes níveis de construção da resiliência urbana: participando da gestão dos sistemas de infraestrutura de modo a conciliar desenvolvimento, proteção e conservação ambiental das cidades por meio do planejamento do uso e ocupação do solo urbano. Essa relação com a cidade torna-se mais profunda quando se analisa a morfologia urbana presente, a passada e a futura sob as lentes dos estudos da Arquitetura e do Urbanismo.

As regulamentações são de competência da administração pública, porém cabe ao arquiteto e urbanista prever e oferecer soluções de infraestrutura viária, energia, saneamento básico, comunicação e mobilidade urbana de 
forma integrada, prevendo a mitigação dos impactos negativos ao meio socioambiental. É de responsabilidade do profissional projetista gerir essas atividades por meio da avaliação e aprovação de projetos, fiscalização e pesquisa por soluções ecologicamente sustentáveis. Sob essa perspectiva, o arquiteto e urbanista é também responsável pela consolidação de novos paradigmas técnicos e educativos, preocupando-se com a formulação de novas referências e assumindo uma importante função social por meio dos projetos arquitetônicos e intervenções urbanas, enquanto um profissional capacitado para pensar e implementar as premissas da sustentabilidade ao planejamento urbano contemporâneo.

\section{O planejamento urbano e o conceito de paisagens de alto desempenho}

Apesar de o processo da urbanização brasileira estar se modificando nas últimas décadas, a concentração da população em metrópoles é um problema que continua se agravando (MARICATO e TANAKA, 2006). Isso implica não só na questão ambiental, como também implica no comprometimento da saúde da população urbana. O avanço do urbano sobre o rural nos países da América Latina reflete um modelo de desenvolvimento que prevê o crescimento das atividades antrópicas acumulativas de capital, sem qualquer preocupação com a sustentabilidade da cadeia 
produtiva do entorno das cidades e, mais, ignora a sustentabilidade dos recursos naturais disponíveis no ecossistema (seja urbano ou rural), vitais para a manutenção da vida no campo e na urbe.

O êxodo rural, caracterizado pela migração populacional de áreas rurais para centros urbanos em busca por melhores condições econômicas e sociais, gerou um acelerado crescimento das cidades, de maneira desordenada e irregular. Reservas ecológicas e matas ciliares, que até então eram áreas sem intervenção, tornaram-se espaços para moradias, sem preocupação com a questão ambiental e o comprometimento da saúde dessa população. O uso e a ocupação do solo urbano sem o devido ordenamento e fiscalização podem gerar problemas socioambientais que já são bastante reconhecidos no cenário das cidades brasileiras.

Os impactos negativos do processo de urbanização, gerados pelas atividades antrópicas mais comuns, são cotidianamente observados e não se restringem somente aos grandes centros urbanos. Médias e pequenas cidades também são afetadas por problemas inerentes à concentração de pessoas no espaço urbano. Os problemas mais frequentes são: aumento da contaminação dos recursos hídricos e do solo; emissões atmosféricas e poluição do ar em níveis alarmantes; alterações do microclima urbano, 
que provocam ilhas de calor e eventos hidrometeorológicos extremos; índice crescente da população vivendo em áreas de risco de inundações, deslizamentos, etc.; especulação imobiliária e supervalorização do solo urbano; falhas no acesso à moradia popular e acentuado processo de favelização; instalações sanitárias precárias e/ou ausência total de saneamento básico em áreas periféricas; déficit de mobilidade urbana provocado pelo aumento significativo do número de automóveis circulando por vias públicas cada vez mais congestionadas; entre outros.

As coberturas superficiais impermeáveis constituem um fator predominante no processo de urbanização e, consequentemente, um aumento significativo do tráfego de veículos, dos grandes deslocamentos, verticalização e adensamento das edificações, além de gastos com toda infraestrutura necessária (MASCARÓ; MASCARÓ, 2009). Nesse caso, os autores se referem à infraestrutura tradicional, aos sistemas de estradas, saneamento básico e todas as atividades necessárias para o desenvolvimento da população e a sua segurança. Conhecido como infraestrutura cinza, onde a paisagem natural é na maioria das vezes modificada por construções, deve ser bem planejada para reduzir os impactos negativos da urbanização.

Em meio a tantos problemas, o planejamento urbano tem sido apontado como uma ferramenta capaz de propiciar às 
cidades construções mais equilibradas (MARICATO e TANAKA, 2006). Segundo Souza e Rodrigues (2004), planejar diz respeito a estruturar o futuro das cidades, buscando precauções para evitar problemas a fim de ganhar possíveis benefícios. Um instrumento essencial para buscar meIhorias na qualidade de vida e garantir o equilíbrio ambiental é o Estatuto da Cidade, que é a denominação oficial da Lei n 10.257 de julho de 2001 e "estabelece normas de ordem pública e interesse social que regulam o uso da propriedade urbana em prol do bem coletivo, da segurança e do bem-estar dos cidadãos, bem como do equilíbrio ambiental" (BRASIL, 2001).

Concomitante ao Estatuto da Cidade, o Plano Diretor Municipal é uma forma de planejar o futuro das cidades e, para Villaça (1999, p. 238):

(...) seria um plano que, a partir de um diagnóstico científico da realidade física, social, econômica, política e administrativa da cidade, do município e de sua região, apresentaria um conjunto de propostas para o futuro desenvolvimento socioeconômico e futura organização espacial dos usos do solo urbano, das redes de infraestrutura e de elementos fundamentais da estrutura urbana, para a cidade e para o município, propostas estas definidas para curto, médio e longo prazos, e aprovadas por lei municipal. 
O Plano Diretor pode ser entendido como um instrumento de planejamento utilizado a curto, médio e longo prazo, para regulamentar e orientar a ação da iniciativa pública e privada na construção da cidade. O Plano deve assumir papel importante na redução das vulnerabilidades socioambientais frente às mudanças ambientais, sejam elas locais, regionais e/ou globais. No entanto, é evidente que apenas redigir tal documento não resolverá nenhum dos problemas enfrentados pela população urbana; é necessário que haja um maior engajamento no processo de planejamento elaborado em conjunto com políticas públicas locais e a participação da comunidade.

A participação dos munícipes é fundamental durante a fase de elaboração do Plano Diretor e, também, para a construção da resiliência urbana que deverá acompanhar a fase de implantação dos projetos e de gestão da cidade, a partir das diretrizes democraticamente estabelecidas no Plano. A população local desempenha um importante papel na identificação dos problemas socioambientais e, portanto, contribui para o planejamento dos espaços e pode opinar acerca da relevância das intervenções e da eficiência das políticas e das práticas urbanísticas.

De fato, o planejamento urbano deve contribuir para o desenvolvimento ordenado das cidades, porém, apesar de leis e planos existirem no Brasil, problemas urbanos con- 
tinuam se agravando. De acordo com Villaça (2005), esse conjunto de leis urbanísticas são detalhadas e complexas, no entanto, são aplicadas com flexibilidade ou, até mesmo, ignoradas em favelas e ocupações ilegais, locais em que o Estado está ausente. Maricato e Tanaka (2006) dizem ainda que os planos e leis são bem-intencionados, apesar disso, são excludentes ou não são aplicados. Diante disso, algumas providências que ajudariam a mudar o "analfabetismo urbanístico" seriam o correto dimensionamento e a adequada qualificação dos problemas urbanos e de suas causas, a maior visibilidade desses problemas perante a sociedade e a formação de agentes públicos e sociais.

Somado a esses aspectos, é de fundamental importância que os planos diretores municipais abordem questões relativas à conservação da natureza, de modo a contemplar soluções técnicas que contribuam para a qualidade ambiental das cidades, como as práticas evidenciadas pela infraestrutura verde, capazes de desempenhar funções ecológicas e sociais para a manutenção e equilíbrio da paisagem urbana construída. De acordo com Santana (2013), atualmente a infraestrutura verde busca trazer soluções urbanas para "renaturalizar" as cidades, priorizando a utilização de tecnologias sustentáveis, a manutenção e a recuperação das áreas verdes.

A forma vegetal característica da paisagem urbana é a ár- 
vore, tendo ligação direta com a arquitetura. Cullen (2015, p. 170) defende que "a arte de combinar edifício e árvore baseia-se numa relação em que a árvore cede a sua riqueza ao edifício, e em que o edifício faz realçar as qualidades arquitetônicas da árvore, de modo a constituírem um conjunto." As árvores são fundamentais, pois controlam a radiação solar, fornecem sombra, reduzem o consumo de energia em épocas quentes, amenizam a poluição do ar, previnem erosões, assoreamento dos rios e ainda auxiliam na infiltração das águas da chuva.

Herzog (2013, p.174) afirma que é preciso "ir do cinza para o verde", ou seja, antes de selecionar as técnicas e os materiais que serão utilizados nos projetos e obras de urbanização, é imprescindível procurar novas soluções que levem à construção de "cidades inteligentes", voltadas para o bem-estar das pessoas. Para tanto, faz-se necessário uma gestão ambiental efetiva e a adoção de práticas que visem manter ou recuperar as funções ecológicas dos ecossistemas locais. Segundo a autora, as paisagens urbanas são essenciais para a qualidade de vida, onde anteriormente a paisagem era cinza com concreto e asfalto, agora é necessário trazer o verde e, consequentemente, garantir bem-estar às pessoas. Destaca ainda que essas paisagens urbanas precisam ter alto desempenho, com função de diminuir enchentes, deslizamentos e poluição, entre outros problemas socioambientais. 
Para entender o que é uma paisagem de alto desempenho, é necessário primeiramente compreender o conceito de "alto desempenho". Ferreira (2001, p. 35) esclarece que o termo "alto" é considerado "excelente, importante, relevante", enquanto o termo "desempenho" se refere à "atuação, comportamento" de um determinado objeto de estudo. Assim, "alto desempenho" representa algo que executa seu serviço com excelência, com qualidade. Segundo Herzog (2013), o termo alto desempenho é utilizado para medir como os materiais e as máquinas se comportam e se atendem ou não às necessidades para as quais foram projetados.

Em relação às cidades, o termo mostra como são igualitárias e cooperativas, já para as paisagens, em destaque, servem para medir a qualidade dos serviços ecossistêmicos e saber se estão garantindo a qualidade de vida e bem-estar aos citadinos. Nesse contexto, o arquiteto pode se apropriar da concepção de paisagens de alto desempenho em seus projetos, contribuindo de forma significativa para uma gestão urbana sustentável, uma vez que esse profissional interfere diretamente na construção e no desenvolvimento das cidades.

Para Herzog (2013), uma cidade que sabe conviver com a natureza é aquela que possui arquitetura sustentável, consome e gera menos resíduos e garante a qualidade das 
águas, bem como a conservação da qualidade do ar e do solo urbano. Um exemplo de paisagem de alto desempenho são os "ecobairros", os quais possuem paisagens com funções ecológicas e sociais, com alto desempenho e baixo impacto. No entanto, fatores histórico-culturais, como o consumo elevado de bens e serviços e a falta de preocupação com a harmonia entre o sistema físico-natural, o sistema social e o sistema construído, apontam um problema de ordem econômica, política e social que assola grande parte das cidades brasileiras.

Nesse limiar, Bogo (2001) acredita que a arquitetura sustentável, bioclimática ${ }^{5}$ e ecológica prova a existência de uma arquitetura insustentável e ecologicamente inadequada. Segundo Pirró (2009), considerando também a afirmação anterior, percebe-se que os conceitos adotados nas escolas de Arquitetura e Urbanismo necessitam de uma reavaliação. Bogo (2001, p. 2) afirma que:

Rever os padrões de vida, também nos remete à arquitetura e ao urbanismo; nos remete aos valores que assumimos quando projetamos e construímos nossas edificações, nossas cidades. Rever estes padrões para o ensino de projeto do ambiente construído, afinal de contas, se produzimos uma arquitetura que representa

5. Arquitetura bioclimática consiste em projetar um edifício levando em conta o clima e as características ambientais do local em que se insere. Pretende-se assim melhorar o conforto ambiental no interior do edifício (LANHAM, GAMA e BRAZ, 2004). 
a "cultura da destruição do planeta", temos que passar a rever estes valores, de forma a começar a pensar numa "cultura de preservação do planeta e da vida na terra", socializando os benefícios, ao invés da prática dominante de socialização dos prejuízos e individualização do lucro.

Atualmente, a sociedade espera do arquiteto um comprometimento com a sustentabilidade (PIRRÓ, 2009). Segundo Farah, Schlee e Tardin (2010), um meio de se atingir essa sustentabilidade é por meio dos projetos paisagísticos, utilizando qualidades naturais e culturais do lugar, com gostos e hábitos de quem o frequenta. Os projetos arquitetônicos paisagísticos contemporâneos buscam a integridade, diversidade e eficiência, valorizando suas singularidades.

A arquitetura paisagística, como área específica de projeto e planejamento dos espaços abertos, fornece projetos para áreas residenciais, condomínios, parques, renovação de setores urbanos; presta, ainda, consultoria especializada na recuperação de áreas degradadas e na formatação de projetos para licenciamento ambiental em áreas naturais, como é o caso das melhorias de desempenho de edificações e áreas urbanas por meio de planos paisagísticos (FARAH, SCHLEE e TARDIN; 2010, p. 225).

Acredita-se que no cenário de crise observado nas cidades, onde as paisagens são constantemente alteradas, acarretando transformações ambientais significativas, perda de florestas e da biodiversidade, deve-se pensar nas contribui- 
ções estratégicas do arquiteto, sem deixar de considerar, porém, o poder de resiliência que o ecossistema urbano possui.

Assim, ressalta-se a importância de conciliar a paisagem natural, composta por áreas verdes, com uma arquitetura projetada a partir dos pressupostos da paisagem de alto desempenho, de modo a intervir na paisagem urbana da forma mais adequada e com vistas a possibilitar uma maior qualidade de vida a uma população culturalmente "cinza". Nesse limiar, destacam-se os projetos urbanísticos que têm como partido a proteção, a conservação e a otimização dos recursos naturais urbanos - além da utilização de técnicas, tecnologia e materiais ecologicamente corretos e sustentáveis aplicados à rede de infraestrutura - e compõem os dispositivos e recursos da infraestrutura urbana verde.

\section{Infraestrutura verde: perspectivas para a sustentabilidade urbana}

Zmitrowicz e Neto (1997) definem infraestrutura urbana como o conjunto de sistemas técnicos necessários para se desenvolver as funções urbanas. As funções devem atender aos aspectos sociais, proporcionando moradia, saúde, trabalho, educação, saúde, segurança e lazer. Deve proporcionar o desenvolvimento de bens e serviços, denotando impacto econômico juntamente com aspecto institucional, 
proporcionando o desenvolvimento das atividades político administrativas da cidade.

Infraestrutura verde não é um conceito novo, porém passou a ser mais abrangente e empregado há pouco tempo. Seus benefícios são para que as cidades não sejam somente mais sustentáveis, mas também para que se tornem aptas a enfrentar os efeitos causados pelos eventos climáticos extremos. De acordo com Herzog (2010, p.4), a infraestrutura verde contém características que permitem "intervenções de baixo impacto na paisagem e alto desempenho, com espaços multifuncionais e flexíveis, que possam exercer diferentes funções ao longo do tempo adaptável às necessidades futuras".

Conforme Benedict e Mcmahon (2006) apud Vasconcellos (2011, p. 30):

(...) a infraestrutura verde pode ser definida como uma rede interconectada estrategicamente planejada e gerida de áreas naturais, paisagens rurais e outras áreas livres que conserva os valores e funções dos ecossistemas naturais, mantém o ar e a água limpos, e proporciona um grande leque de benefícios para o homem e a vida silvestre.

A infraestrutura verde, portanto, contribui para a qualidade ambiental e para a construção da resiliência do espaço urbano. Com papel fundamental para as adaptações técnicas 
e tecnológicas necessárias no sistema de infraestrutura das cidades, ela colabora com o aumento da permeabilidade do solo, melhora a qualidade de vida das pessoas, além de inúmeros outros benefícios. Assim, a infraestrutura verde traz benefícios para o meio ambiente, para a conservação dos recursos naturais e, consequentemente, para a salubridade das cidades e para a saúde dos seus cidadãos.

Quando a expansão da malha urbana compromete a qualidade ambiental das cidades, também compromete a qualidade de vida dos citadinos. A pressão do uso e ocupação do solo sobre áreas de proteção ambiental, sem se preocupar com as características naturais, sociais, econômicas e culturais da região, gera um conflito entre o crescimento e a conservação da natureza (CORMIER e PELLEGRINO, 2008), logo, os problemas decorrentes dessa incompatibilidade perpassam para os setores da organização socioespacial das cidades, conferindo ao espaço urbano diversos problemas e conflitos socioambientais.

Herzog (2010) afirma que, se bem planejada e implantada, a infraestrutura verde servirá como suporte para a resiliência das cidades, mas para isso é necessário conhecer a biodiversidade local, preservando as áreas alagadas e as encostas instáveis. Atesta que essa nova infraestrutura, além de buscar por transportes alternativos não poluentes, também auxilia na integração entre os transportes ativos: caminha- 
da para pedestres e bicicletas. Desse modo, a infraestrutura verde causa benefícios a todos, estimulando atividades recreativas e auxiliando na conscientização da preservação da natureza.

A infraestrutura urbana pode ser aplicada em diferentes escalas, como particular, local, estadual, regional ou nacional. As intervenções de escala particular referem-se, por exemplo, às edificações e aos seus jardins e quintais. Nesse caso, podem ser utilizados tetos, paredes e muros verdes. No caso dos telhados verdes, são vastas as contribuições sustentáveis, pois "absorvem água das chuvas, reduzem o efeito da ilha de calor urbano, contribuem para a eficiência energética das edificações, criam hábitat para vida silvestre e, de fato, estendem a vida da impermeabilização do telhado" (CORMIER; PELLEGRINO, 2008, p. 135). Já as paredes verdes são utilizadas quando se tem pouca área para vegetação ou servindo para sombreamento (HERZOG, 2010). Os dois sistemas melhoram a qualidade da água e do ar, regulam o clima e as enchentes, auxiliam na educação e no valor estético.

$\mathrm{Na}$ escala local, podem-se citar os greenways ${ }^{6}$ ou as práticas que contribuem para a melhor gestão das águas plu-

6. Espaço livre linear estabelecido ao longo de um corredor natural para caminhadas, ciclismo e outros usos recreativos que liga parques, reservas naturais, locais culturais e/ou históricos (BENEDICT e MCMAHON, 2006 apud VASCONCELLOS, 2011, p. 35). 
viais, como os jardins de chuva, canteiros pluviais, pavimentação permeável, etc. Os greenways são utilizados para conectar parques já existentes. Dessa forma, são espaços lineares para caminhadas, ciclismo, etc., estabelecidos ao longo de um corredor natural ligando parques, reservas naturais, dentre outros locais (BENEDICT; MCMAHON, 2006 apud VASCONCELLOS, 2011).

Já para a gestão das águas pluviais, pode ser feito um jardim de chuva. Segundo Herzog (2010, p. 07), os jardins de chuva "são jardins em cotas mais baixas que recebem as águas da chuva de superfícies impermeáveis adjacentes". Esse sistema funciona como purificador das águas pluviais, além de ser uma forma de detenção que diminui o fluxo de água para os bueiros e canais.

Outras abordagens, segundo Herzog (2010), foram desenvolvidas para diminuir o consumo de energia e melhorar o conforto das pessoas, são canteiros pluviais, biovaletas, bacias de retenção, bacias de detenção e os pavimentos porosos.

Os canteiros pluviais, por exemplo, recebem as águas de escoamento superficial e possuem capacidade de infiltração, evaporação e/ou evapotranspiração. São equipamentos de drenagem eficientes para a redução da taxa de escoamento superficial sobre as áreas impermeabilizadas 
das cidades e possuem valor estético na composição da paisagem verde urbana. Já o sistema de biovaleta recebe águas contaminadas promovendo sua filtragem, podendo ser locadas em estacionamentos e ao longo das vias, consideradas como jardins lineares preenchidos por vegetação, servindo como reguladoras de enchentes.

As lagoas pluviais ou bacias de retenção recebem as águas das chuvas e as armazenam. Apesar de demandar mais espaço por armazenar grandes volumes de água, apresentam fatores relevantes como a melhora da qualidade da água, regulam o clima e as enchentes, possuem valor estético e ainda servem para recreação, lazer e ecoturismo.

As lagoas secas ou bacias de detenção possuem a mesma função que a anterior, a única diferença é que não armazenam a água, apenas auxiliam em épocas de chuvas, retardando a entrada da água no sistema de drenagem. Há ainda os pavimentos porosos, que permitem a infiltração de uma porcentagem das águas, reduzem o escoamento superficial das águas de chuva e podem ser usados em calçadas, estacionamentos, quintais, praças ou parques.

Em relação à escala estadual, regional ou nacional, pode-se propor ligações da paisagem ou proteção ao habitat dos animais. Nesse caso, a infraestrutura verde pode ser conectada com os ecossistemas e as paisagens pelo siste- 
ma de hubs e links. Os hubs proporcionam espaços para as plantas nativas e comunidades de animais e podem ser grandes reservas ou áreas de proteção, como refúgios nacionais de vida silvestre ou parques estaduais. Já os links são as ligações da paisagem (landscape linkages), que conectam parques, reservas e áreas naturais existentes. Esse sistema permite que plantas e animais se reproduzam e funcionam ainda como corredores, conectando ecossistemas e paisagens (BENEDICT; MCMAHON, 2006 apud VASCONCELLOS, 2011).

Outro exemplo são os alagados construídos ou wetlands, que, conforme Herzog (2010, p. 06) e Vasconcellos (2011, 196 p. 141), "recebem as águas pluviais, promovem a retenção e a remoção de contaminantes". Esse sistema pode ser aplicado desde a escala local, em pátios de edifícios, até a escala regional, ocupando grandes áreas urbanas.

No Brasil, constatam-se wetlands naturais em áreas pantanosas dos estados do Amazonas, Mato Grosso e Mato Grosso do Sul (Pantanal). SALATI (2000) apresenta a primeira tentativa de utilizar um sistema de wetland construído para purificação das águas urbanas, através de um lago artificial nas proximidades de um córrego altamente poluído (Rio Piracicamirim), localizado em Piracicaba/SP. Inicialmente, as experiências foram satisfatórias e os trabalhos foram continuados a partir de 1985, desenvolvendo novas 
tecnologias, com o objetivo de aumentar a eficiência do sistema com menores custos de investimentos.

Como foi possível observar nessa leitura, a aplicação e incorporação da infraestrutura verde nas diferentes escalas permite a funcionalidade da paisagem, melhora a qualidade do ar, previne enchentes e inundações, melhora a mobilidade urbana, entre outros benefícios, ou seja, a infraestrutura verde pode ser considerada como uma estratégia para a conservação e proteção da natureza e para a sustentabilidade da vida no espaço urbano.

\section{Considerações finais}

O presente artigo buscou mostrar caminhos para a leitura de um urbanismo sustentável, proporcionando visibilidade à infraestrutura verde como instrumento atual para o planejamento urbano e arquitetônico. A partir de um repertório teórico e analítico, apresentou a infraestrutura verde como uma possível solução para os problemas atuais de drenagem, inundações, deslizamentos, entre outros.

Os preceitos utilizados nos projetos e obras de infraestrutura e equipamentos urbanos sustentáveis podem ser aplicados para tornar as cidades menos impactantes ao meio ambiente e com maior qualidade de vida para a população. Podem ser utilizados em edificações, locais públicos, como praças, parques e vias públicas. Vários são os métodos 
atuais de contribuir para a sustentabilidade urbana a partir de intervenções diretas, como: telhados verdes, jardins de chuva, wetlands, pavimentação permeável, parques lineares, etc. Cabe ao profissional responsável analisar qual tipologia é mais adequada para cada situação. Diante de diversos problemas observados, tanto em relação ao planejamento quanto à gestão dos sistemas urbanos, os arquitetos e urbanistas têm um papel fundamental para o desenvolvimento de novas diretrizes políticas e técnicas, bem como colaborar na utilização de recursos materiais e tecnológicos ecologicamente adequados.

A atuação do profissional de Arquitetura e Urbanismo fortalece o quadro interdisciplinar de planejamento das cidades, que, sob a perspectiva do urbanismo sustentável, visa à integração entre os sistemas naturais e os sistemas construídos, contribuindo de forma efetiva à organização do espaço urbano, via infraestrutura verde. Vale ressaltar que, além de projetar, cabe a esse profissional despertar o interesse das diferentes esferas da sociedade urbana para uma nova forma de conceber e se relacionar com o ambiente em que se vive, em prol de uma melhor qualidade de vida nas cidades.

A infraestrutura verde tem em comum com a arquitetura a busca pela saúde e bem-estar das pessoas, sendo indispensável para o planejamento urbano. Cormier e Pellegrino (2008) acreditam que os maiores desafios para implantar a 
infraestrutura verde são em relação aos moradores das cidades e na identificação com ela. E para ocorrer essa conexão, inicialmente é por meio da educação, mostrando sua importância e sua funcionalidade.

É necessário, portanto, a percepção da população sobre o planejamento e a proteção dos espaços verdes, pois a infraestrutura verde é desenvolvida exatamente para que a ocupação aconteça sem riscos à população e para proporcionar serviços ecológicos em benefício das pessoas (HERZOG, 2009 apud VASCONCELLOS, 2011).

Segundo O'Reilly, Magalhães e Rossi (2013), os seres humanos dependem dos serviços dos ecossistemas para sua sobrevivência, pois esses auxiliam na regularização do clima e para produção de alimentos. Apesar de a implementação da infraestrutura verde ser mais cara, é um investimento a longo prazo, em que ocorre uma diminuição dos gastos com água, energia, transporte e saúde pública.

Os arquitetos, urbanistas e paisagistas são qualificados juntamente com outros especialistas para realizar projetos baseados na sustentabilidade e na infraestrutura verde, integrando os edifícios com a infraestrutura urbana já existente, colaborando na preservação e recuperação do meio ambiente, além de aproveitar os recursos que a natureza disponibiliza e aumentar a relevância social e ambiental de 
seus projetos (CORMIER; PELLEGRINO, 2008).

O arquiteto e urbanista, em atribuição à sua função, deve comprometer-se em buscar alternativas sustentáveis na hora de projetar e reformar edificações, ou então revitalizar um espaço urbano. Porém é necessário analisar como essa nova infraestrutura se conectará com os diferentes tipos de cultura e identidade regional.

Para Benedict e Mcmahon (2006 apud Vasconcellos, 2011, p.33), "muitos dos elementos da infraestrutura verde já estão no local, contudo, somente em rede é que efetivamente possuem valor." Nesse caso, o arquiteto e urbanista pode contribuir promovendo a inter-relação entre os diferentes elementos (ruas arborizadas, tetos verdes, etc.), de modo com que todos eles trabalhem juntos como um sistema funcional.

Herzog e Rosa (2010) acreditam que, para melhorar definitivamente os espaços urbanos, as tipologias citadas podem ser incorporadas em áreas já urbanizadas quando houver reformas e adaptações das edificações e em espaços impermeabilizados existentes. Portanto, é importante ressaltar que as técnicas de reurbanização com vistas à sustentabilidade também sejam enfatizadas durante a formação e qualificação dos profissionais atuantes na construção da paisagem urbana. 
Dessa forma, ao concluir o curso de graduação, o arquiteto e urbanista deve estar preparado para se inserir no mercado de trabalho como um profissional qualificado para atender às novas demandas, capaz de apontar soluções adequadas para o planejamento e para a gestão sustentável dos sistemas urbanos, considerando sempre a linha tênue entre a conservação dos recursos naturais e a garantia da qualidade de vida para os citadinos nos projetos arquitetônicos e urbanísticos.

\section{Referências}

ACSELRAD, Henri. Sentidos da sustentabilidade urbana. In: ACSELRAD, Henri (Org.). A duração das cidades: sustentabilidade e risco nas políticas urbanas. 2. ed. Rio de janeiro: Lamparina, 2009.

Discursos da sustentabilidade urbana. Revista Brasileira de

Estudos Urbanos e Regionais. Recife, n.1. p.79-90, 1999.

BATISTA, Elieser; CAVALCANTI, Roberto Brandão; FUJIHARA, Marco Antonio. Caminhos da sustentabilidade no Brasil. São Paulo: Terra das artes, 2005.

BOGO, Amilcar José. O conceito de desenvolvimento sustentável incorporado ao ensino e ao projeto do ambiente construído: algumas considerações. In: VI Encontro Nacional e III Encontro Latino-Americano sobre Conforto no Ambiente Construído, 2001, Anais... São Pedro, Brasil, 6 f. Disponível em: <http://www.infohab.org.br/acervos/resumo/page/2062/codigo_biblio/26340/cod/1 >. Acesso em: 20 jan. 2016.

BONDER, Cintia. Desenvolvimento sustentável como uma forma de mitigar o impacto negativo da globalização nas comunidades locais.

Revista Virtual Textos \& Contextos. n. 2, ano II, dez/2003. Disponível em: < revistaseletronicas.pucrs.br/ojs/index.php/fass/article/download/.../733>. Acesso em: 06 fev. 2016. 
BRASIL. Lei n 10.257 de julho de 2001. Regulamenta os arts. 182 e 183 da Constituição Federal, estabelece diretrizes gerais da política urbana e dá outras providências. Diário Oficial da União, Brasília, 10 jul., 2001. Disponível em: <http://www.planalto.gov.br/ccivil_03/leis/ LEIS_2001/L10257.htm>. Acesso: 06 fev. 2016.

CABRERA, Luis Carlos. Afinal, o que é sustentabilidade? Revista você. S/A. 2009. Disponível em:<http://planetasustentavel.abril.com. $\mathrm{br} /$ noticia/desenvolvimento/conteudo_474382.shtml>. Acesso em: 06 fev. 2016.

CORMIER, Nathaniel S.; PELLEGRINO, Paulo Renato Mesquita. Infra-estrutura verde: uma estratégia paisagística para a água urbana. Paisagem Ambiente: ensaios, São Paulo, n. 25, p.125-142, 2008. Disponível em: <http://www.espiral.fau.usp.br/arquivos-artigos/ 2008-Nate\&Paulo.pdf>. Acesso em: 08 nov. 2015.

CULLEN, Gordon. Paisagem Urbana. Lisboa/Portugal: edições 70, 2015. 205p.

DEMANTOVA, Graziella. Sustentabilidade e o futuro das cidades: a arquitetura como indutora de transformações sociais e ambientais. Revista Arquitextos. V. 150.05, ano 13, nov/2012. Disponível em: <http://www.vitruvius.com.br/revistas/read/arquitextos/13.150/4574>. Acesso em: 29 jan. 2016.

FARAH, Ivete; SCHLEE, Monica Bahia; TARDIN, Raquel. Arquitetura paisagística contemporânea no Brasil. São Paulo: Editora Sena São Paulo, 2010. 232p.

FERREIRA, A. B. H. Miniaurélio século XXI escolar: o minidicionário da língua portuguesa. 4. Ed. Rio de Janeiro: Nova Fronteira, 2001. 790p.

FURTADO, Fátima. Cidades resilientes: considerações conceituais. In: FURTADO, Fátima. PRIORI JR., Luiz. ALCÂNTARA, Edinéa. Mudanças climáticas e resiliência de cidades. Recife: Pickimagem, 2015. p.19-32.

HERZOG, Cecília Polacow. Cidades para todos: (re)aprendendo a conviver com a natureza. 1. ed. Rio de Janeiro: Mauad X: Inverde, 2013.

Infra-estrutura verde para cidades mais sustentáveis. In: 
Seção teoria e práticas em construções sustentáveis no Brasil: subsídios a implementação de gestão e insumos para construção e compras públicas sustentáveis no estado do Rio de Janeiro. Rio de Janeiro: Governo do Estado do Rio de Janeiro e ICLEI-Brasil, 2010. Disponível em: <http://download.rj.gov.br/documentos/10112/1312245/ DLFE-56336.pdf/14_SECAOIV_3_INFRA_VERDE_docfinal_rev.pdf > . Acesso em: 08 nov. 2015.

HERZOG, Cecília Polacow; ROSA, Lurdes Zunino. Infraestrutura verde: sustentabilidade e resiliência para a paisagem urbana. Revista LABVERDE FAU/USP, São Paulo, n. 1, p. 92-115, out. 2010. Disponível em: <http://www.revistas.usp.br/revistalabverde/article/ view/61281/64217>. Acesso em: 09 nov. 2015.

HISAYASU, Thelma Yumi Sanda; PELLEGRINO, Paulo Renato Mesquita. Infraestrutura verde para setor de urbanização informal em área de mananciais na região metropolitana de São Paulo. Revista FAU/USP. 2009. Disponível em: <http://www.fau.usp.br/disciplinas/tfg/tfg_online/tr/091/a064.html>. Acesso em: 08 nov. 2015.

JACOBI, Pedro. Educação ambiental, cidadania e sustentabilidade. Cadernos Pesquisa, São Paulo, v. 118, n.1, p.189-205, 2003. Disponível em: <http://www.scielo.br/pdf/cp/n118/16834.pdf>. Acesso em: 01 fev. 2016.

Poder local, políticas sociais e sustentabilidade. Revista Saúde e Sociedade, 8(1), p. 31-48, 1999. Disponível em: <http://www. scielo.br/pdf/sausoc/v8n1/04>. Acesso em: 24 jul. 2017.

KARPINSK, Luisete A. et al. Gestão diferenciada de resíduos da construção civil: uma abordagem ambiental. Porto Alegre: Edipucrs, 2009. 163 p. Disponível em: <http://www.sinduscondf.org.br/portal/ arquivos/GestaodeResiduosPUCRS.pdf>. Acesso em: 01 fev. 2016.

LANHAM, Ana; GAMA, Pedro; BRAZ, Renato. Arquitectura bioclimática: perspectivas de inovação e futuro. Lisboa: 2004. Disponível em: $<$ http://www.gsd.inesc-id.pt/ pgama/ab/Relatorio_Arq_Bioclimatica. pdf>. Acesso em: 18 fev. 2016.

LEMOS, Maria Fernanda. Planejamento urbano para enfrentamento de riscos ambientais, redução de vulnerabilidade sócio-climática e adaptação de cidades. In: Simpósio Temático Urbanismo na Sociedade de Risco, 2010, Rio de Janeiro. Violência Urbana e Vulnerabilidade 
Ambiental. Anais... Rio de Janeiro: 2010. Disponível em: <http://www. anparq.org.br/dvd-enanparq/simposios/161/161-800-1-SP.pdf. > . Acesso em: 19 fev. 2016.

MARICATO, Erminia; TANAKA, Giselle. O planejamento urbano e a questão fundiária. Ciência Hoje, v.38, p.16-23, 2006.

MASCARÓ, Lucia; MASCARÓ Juan José. Ambiência Urbana. 6. ed. Porto Alegre: Masquatro Editora, 2009. 200p.

MENDONÇA, Francisco. Resiliência urbana: concepções e desafios em face de mudanças climáticas globais. In: FURTADO, Fátima.

PRIORI JR, Luiz. ALCÂNTARA, Edinéa. (Org.). Mudanças climáticas e resiliência de cidades. Recife: Pickimagem, 2015. p.45-60.

O'REILLY, Érika de Mattos; MAGALHÃES, Vinicius Macedo; ROSSI, Angela Maria Gabriela. O impacto da infraestrutura verde na qualidade de vida e no meio ambiente. In: IV Simpósio de Pós-Graduação em Engenharia Urbana / I Encontro Nacional de Tecnologia Urbana. Anais... Rio de Janeiro: 2013. 06 f. Disponível em: <http://www.laburb.poli.ufrj.br/publicacoes/INFRA-84.pdf>. Acesso em: 20 jan. 2016.

PIRRÓ, Lucia Fernanda de Souza. Sustentabilidade: da paisagem urbana ao edifício. Revista Belas Artes. 2009. Disponível em: <http:// www.belasartes.br/revistabelasartes/downloads/artigos/1/revista-ba-sustentabilidade-paisagem.pdf> Acesso em: 16 jan. 2016.

RATTNER, Henrique. Prefácio. In: ACSELRAD, Henri (Org.). A duração das cidades: sustentabilidade e risco nas políticas urbanas. 2. ed. Rio de janeiro: Lamparina, 2009.

SALATI, Eneas. Controle da qualidade da água através de sistemas de wetlands construídos. FBDS- Fundação Brasileira para o Desenvolvimento Sustentável, 2000. 19 p. Disponível em: <http:// www.fbds.org.br/Apresentacoes/Controle_Qualid_Agua_Wetlands_ ES_out06.pdf>. Acesso em: 31 nov. 2015.

SANTANA, Gisela. Marketing da "sustentabilidade" habitacional: lançamentos imobiliários e ecologia urbana: em busca do equilíbrio. Rio de Janeiro: Mauad X: Inverde, 2013.

SILVA, Evander de Oliveira. Cidades resilientes: novos rumos para uma cidade do futuro. JusBrasil. Disponível em: <http://evanderoliveira.jusbrasil.com.br/artigos/152036518/cidade-resilientes-novos-rumos- 
-para-uma-cidade-do-futuro>. Acesso em: 10 ago. 2017.

SOUZA, Marcelo Lopes de; RODRIGUES, Glauco Bruce. Planejamento urbano e ativismos sociais. São Paulo: UNESP, 2004. 136p.

VASCONCELLOS, Andreia Araújo de. Infraestrutura verde aplicada ao planejamento da ocupação urbana na bacia ambiental do Córrego D'Antas, Nova Fraiburgo/RJ. Dissertação (mestrado) Pontifícia Universidade Católica do Rio de Janeiro, Departamento de Engenharia Civil, 2011. 187 f. Disponível em: <http://www.urb.puc-rio. $\mathrm{br} /$ dissertacao/dissertacao_andrea_araujo.pdf >. Acesso em: 15 nov. 2015.

VILLAÇA, Flávio. As ilusões do plano diretor. São Paulo, 2005.

. Dilemas do plano diretor. In: CEPAM. O município no século XXI: cenários e perspectivas. São Paulo: Fundação Prefeito Faria Lima - Cepam, 1999. p. 237 - 247.

ZMITROWICS, Witold; ANGELIS NETO, Generoso de. Infra-estrutura urbana. São Paulo: EPUSP, 1997.

Recebido em: 08/05/2018

205

Aprovado em: 31/07/2018 